\title{
Finnish Enterprise Agile Transformations: A Survey Study
}

\author{
Petri Kettunen $^{1(\bowtie)}$, Maarit Laanti ${ }^{2}$, Fabian Fagerholm ${ }^{1,3}$, \\ Tommi Mikkonen $^{1}$, and Tomi Männistö ${ }^{1}$ \\ ${ }^{1}$ University of Helsinki, Helsinki, Finland \\ \{petri.kettunen, fabian. fagerholm, tommi.mikkonen, \\ tomi.mannisto\}@helsinki.fi \\ 2 Nitor Delta, Helsinki, Finland \\ maarit.laanti@nitor.com \\ 3 Blekinge University of Technology, Karlskrona, Sweden \\ fabian.fagerholm@bth.se
}

\begin{abstract}
Modern large software-intensive development organizations are nowadays more and more often believed to transform their structures and operations towards large-scale agility in search for higher performances. Based on a survey conducted in Finland in 2018, in this paper we explore the current state of the affairs with respect to how extensively organizations are actually transforming themselves, in what ways this takes place in practice and for what goals. Most of the respondents were in large organizations. The results show that the majority of the surveyed respondents indicated that their organizations have conducted agile transformations or are currently doing so. Different strategies and tactics have been used in the transformations, but markedly the respondents reported most that the company has had external consultants (subcontracting) to assist in the change. The most important goals aimed to be achieved with agile means were productivity and quality (operative) and responsiveness to customer/market changes (new features). Notably only very few respondents reported their organizations to be currently non-agile (do not use at all agile methods in software development).
\end{abstract}

Keywords: Agile transformation $\cdot$ Enterprise agile $\cdot$ Scaled agile $\cdot$ Large-scale agile software development $\cdot$ Survey

\section{Introduction and Background}

Agile methods and practices are nowadays mainstream in software development organizations. In large organizations agile software development is scaled in size to multiple teams and project program levels (large-scale agile). However, agile practices and ways of working are also increasingly applied in other functional areas and operations of large companies. Moreover, modern software-intensive companies facing digitalization are gearing to become agile enterprises - nimble and flexible with business agility [1]. These companies may be performing enterprise agile transformations. 
When agile software development methods and practices are extended and scaled up to enterprise levels in large organizations, new competences and organizational capabilities beyond software engineering are required to conduct successful agile transformations $[1,2]$. These include such as organization design and dynamics, production economics and product/service solution management which are all distinct disciplines of their own. Each organization should know their needs and goals of agility $[3,4]$.

Agile research tends to be lagging behind industrial practice. Assuming that large companies are in reality performing agile transformations, there is a need for more empirical research. Relevant research topics include how to conduct large-scale agile transformations, what the important context factors are, and what the role of the established agile scaling frameworks (e.g., SAFe) is [5]. Our research problem is to understand why and how different companies want to change with agile means including whether companies have conducted agile transformations and to what extent, and how beneficial and successful their particular changes have been. Digitalization is one of our key context factors. In this paper we present current results with respect to agile transformations in large organizations based on our recent survey study done in Finland. We have reported related results about agile scaling frameworks (SAFe) elsewhere [6]. Notably here we see scaled agile in software development as a means for enterprise-level agility in larger organizations.

Various Agile surveys have been conducted earlier, but nowadays especially the fast progress of digitalization makes it topical for different organizations. Agile is expanding from pure software industry to traditional, non-software industries and scaling in enterprises. Considering prior and related survey works, one of the most internationally known ones is the annual State of Agile survey by Version One [7]. In Finland a particular scientific survey was done in 2012 [8]. In addition, the annual Finnish Software Industry Survey has addressed agility-related points [9]. Our guiding motivations for this survey research were to investigate the current state of the agile development in Finland taking into account enterprise-level agility and also non-ICT companies.

\section{Survey Research Design}

The overall purpose of our survey research was to examine the current state of Agile and enterprise agility in Finland. To begin with, we were interested in measuring how widely agile methods and practices are currently applied in industrial practice and how that is evolving.

Following this line of thinking we defined a broad range of topics and issues ranging from basic ones of agile software methods and practices to company-wide matters. Moreover, we aimed to investigate not only the current whereabouts but also the future intentions of the companies. The target population was intentionally not limited to software companies since we were also interested in non-software companies currently facing digitalization and becoming more software-intensive (i.e., companies in other industries than IT). 
The survey questionnaire was composed by starting from our selected main research themes and interests stated above. The questionnaire structure comprised the following primary sections:

1. Company's state of agile

2. Agile company transformation

3. Agile future of the company

The specific questions were compiled on the one hand by referring to prior surveys for comparison purposes (e.g., [7, 8]) and by deriving from our industrial experiences and our prior works (e.g., [3]) on the other hand. The draft questionnaire was first piloted both in our industrial and academic organizations. The final version consisted of total of 50 questions (including background information items). Certain questions were only applicable depending on their preceding selector questions (e.g., whether SAFe is in use or not). The survey was available in both Finnish and in English (translated by the first author).

For data collection the survey was implemented as a web-based online questionnaire with the Finnish/English language choice. The questionnaire was distributed through social media and a proprietary industrial mailing list mass postings to over 600 people, and it was open for responding for four weeks during November and December 2018.

\section{Results}

In this paper we present the subset of the full survey result data directly related to the research topic of large agile transformations. In the survey the following questions addressed specifically that area:

- When has there been executed or planned agile transformation in Your company most recently? ${ }^{1}$

- The question was instructed as follows: "Extensive (covering the entire software development) change to adopt agile methods, practices and ways of working"

- How is Your company/has Your company been executing agile transformation?

- Why does Your company want to become more agile?

- Is Your company conducting or planning an agile transformation?

- This question was applicable for non-agile company respondents only (i.e., the ones who reported their company not to use agile methods at all).

Next, we present the results data of the above main questions. A total of over 400 replies were received, but only $28 \%$ of the respondents finished the questionnaire. Not all replied to all questions. In this paper, we report only on the data of those respondents (119) who replied to the last question in the questionnaire sequence (background

\footnotetext{
${ }^{1}$ In this paper we show the English translations of the Finnish questions regardless of which language the respondents have used.
} 
information of the respondent). In our web-tool implementation of the questionnaire we did not restrict the finishing with mandatory questions.

The key respondent demographic information is presented in Tables 1 and 2 . Notably most of the respondents $(74 \%)$ were from large or very large organizations.

Table 1. What is the size of Your organization?

\begin{tabular}{l|l|l}
\hline (multi choice not allowed) & $\begin{array}{l}\mathrm{n}(\mathrm{N}=119, ' \text { No answer' choice } \\
\mathrm{N} / \mathrm{A}=4)\end{array}$ & $\begin{array}{l}\% \text { (out of } \\
\mathrm{N})\end{array}$ \\
\hline $\begin{array}{l}\text { Very large (more than 5000 } \\
\text { persons) }\end{array}$ & 45 & 38 \\
\hline Large (more than 250 persons) & 43 & 36 \\
\hline Middle-sized (50-250 persons & 12 & 10 \\
\hline Small (10-50 persons) & 12 & 10 \\
\hline Micro (less than 10 persons) & 3 & 3 \\
\hline
\end{tabular}

Table 2. What is the primary sector (line of business) of Your company?

\begin{tabular}{l|l|l}
\hline (top 3) (multi choice not allowed) & $\mathrm{n}(\mathrm{N}=117, \mathrm{~N} / \mathrm{A}=2)$ & $\%$ \\
\hline C1 ICT sector (including consulting), information technology & 39 & 33 \\
\hline C2 Financial sector (banking, insurance) & 27 & 23 \\
\hline C4 Telecom services & 13 & 11 \\
\hline
\end{tabular}

Table 3 shows that approximately $40 \%$ of the responses indicated that the respondents' organizations have already conducted agile transformations ('Done') while $30 \%$ stated that they are currently (at the time of the survey in 2018) doing that ('In progress'). Furthermore, it tabulates the distributions according to the top industry sectors (see Table 2).

Table 3. When has there been executed or planned agile transformation in Your company most recently?

\begin{tabular}{l|l|l|l|l|l}
\hline (multi choice allowed) & $\begin{array}{l}\mathrm{n}(\mathrm{N}=117, \\
\mathrm{N} / \mathrm{A}=6)\end{array}$ & $\begin{array}{l}\%(\text { out } \\
\text { of } \mathrm{N})\end{array}$ & $\begin{array}{l}\mathrm{C} 1 \\
(\mathrm{~N}=34)\end{array}$ & $\begin{array}{l}\mathrm{C} 2 \\
(\mathrm{~N}=27)\end{array}$ & $\begin{array}{l}\mathrm{C} 4 \\
(\mathrm{~N}=13)\end{array}$ \\
\hline Done over 5 years ago & 15 & 13 & 11 & 0 & 1 \\
\hline Done 2-5 years ago & 22 & 19 & 9 & 3 & 6 \\
\hline Done some one year ago & 14 & 12 & 1 & 3 & 2 \\
\hline In progress & 35 & 30 & 5 & 16 & 5 \\
\hline $\begin{array}{l}\text { Planned, implementation } \\
\text { schedule open }\end{array}$ & 8 & 7 & 2 & 3 & 0 \\
\hline $\begin{array}{l}\text { Under planning (e.g., } \\
\text { pilots) }\end{array}$ & 5 & 4 & 0 & 4 & 0 \\
\hline $\begin{array}{l}\text { Not done/planned agile } \\
\text { transformation }\end{array}$ & 20 & 17 & 8 & 1 & 0
\end{tabular}


Table 4 gives insights about how the respondents perceived their organizations' transformations conducted in practice. The organizations have applied both bottom-up and top-down approaches to their transformations. The respondents indicated the utilization of external consulting support most (43\%).

Table 4. How is Your company/has Your company been executing agile transformation?

\begin{tabular}{l|l|l}
\hline (multi choice allowed) & $\begin{array}{l}\mathrm{n}(\mathrm{N}=84, \\
\mathrm{N} / \mathrm{A}=2)\end{array}$ & $\begin{array}{l}\% \text { (out of } \\
\mathrm{N})\end{array}$ \\
\hline $\begin{array}{l}\text { The company has a strategy for adopting agile ways of } \\
\text { working and practices }\end{array}$ & 24 & 29 \\
\hline $\begin{array}{l}\text { The company has initiated the change top-down in the } \\
\text { organization }\end{array}$ & 26 & 31 \\
$\begin{array}{l}\text { The company has initiated the change bottom-up (from } \\
\text { teams) in the organization }\end{array}$ & 34 & 40 \\
\hline $\begin{array}{l}\text { There is a dedicated agile support team in the company } \\
\begin{array}{l}\text { The company has had external consultants (subcontracting) to } \\
\text { assist in the change }\end{array}\end{array}$ & 37 & 44 \\
\hline $\begin{array}{l}\text { Self-made transformation in the company } \\
\text { In other ways (how) }\end{array}$ & 13 & 61 \\
\hline
\end{tabular}

We did not ask directly why companies conduct their agile transformations. However, insights to that can be inferred from what goals they target to achieve with agility. Table 5 summarizes what the respondents ranked the five most important reasons for becoming agile for their organizations.

Table 5. Why does Your company want to become more agile?

\begin{tabular}{l|l|l}
\hline top 5, multi choice allowed) & $\begin{array}{l}\mathrm{n}(\mathrm{N}=85, \\
\mathrm{N} / \mathrm{A}=2)\end{array}$ & $\begin{array}{l}\% \text { (out } \\
\text { of N) }\end{array}$ \\
\hline Productivity and quality (operative) & 62 & 73 \\
\hline Responsiveness to customer/market changes (new features) & 56 & 66 \\
\hline Job satisfaction & 46 & 54 \\
\hline $\begin{array}{l}\text { Fast/continuous organizational learning in rapidly changing } \\
\text { operating environments }\end{array}$ & 43 & 51 \\
\hline $\begin{array}{l}\text { Competitive and desirable products (new product } \\
\text { development) }\end{array}$ & 41 & 48 \\
\hline
\end{tabular}

Finally, in contrast we were also interested in non-agile organizations (i.e., who respond to the question: 'How widely does Your company use agile methods in software development? - We do not use at all'). Only 6 out of the 119 respondents were in non-agile organizations. Most of them (5) stated that their organization are not active to transform, either ('Is Your company conducting or planning an agile transformation? - Not in progress/planning'). 


\section{Discussion}

Our key discovery in this study is that agile transformations have been conducted in this Finnish sample of organizations already several years ago (see Table 3). They are also ongoing in different industry sectors.

Another key insight is that different large organizations appear to be using different strategies and tactics for their agile transformations (see Table 4). There is emphasis to have external consultants (subcontracting) to assist in the change. That could indicate that the companies have realized to need new competencies and/or additional resources to perform their transformations in sustainable ways. Unsurprisingly company internal efficiencies were scored the highest goals to be attained with agile means but also the external, customer-related goals of agility are important. Such performance effects require systematic company-wide capabilities that agile transformations may bring.

In comparison to the related studies, Rodríguez et al. investigated agile and lean adoption (usage of agile and lean methods) in software developing organizations [8]. They do not address agile transformation in the large organizational scale like we do. With respect to our results ('The company has initiated the change top-down in the organization' in Table 4) one particular comparable point in their study was that top management commitment was the most significant challenge in agile and lean adoption. Like in our results (Table 5), productivity was the most important goal. Notably, though, in our survey questionnaire agile and lean were not combined.

VersionOne also reports agile adoption (usage of agile practices) rather than transformation [7]. However, their 2018 survey concludes that "agile is expanding within the enterprise" for instance with product roadmapping. One comparable result point in their study is that $30 \%$ of the respondents' organizations have been practicing agile development methods for more than 5 years while in our case some $13 \%$ of the respondents reported their organizations to have performed agile transformation in that time frame ('Done over 5 years ago' in Table 3). In contrast to our results (Table 5) and the study by Rodríguez et al. [8], the most important goal for agile adoption was reported to be accelerated delivery speed while productivity was ranked third.

With respect to non-agile organizations VersionOne reports that $97 \%$ of respondents' organizations practice agile development methods [7]. In our survey the comparative value is $94 \%$. Strikingly, Rodríguez et al. reported $42 \%$ of organizational units with no agile nor lean methods usage [8]. This could be due to the differences in the sample population or that the organizations have progressed since that time (2012).

Considering the comparability and generalization, we acknowledge that a validity concern in our results is whether all the respondents have interpreted and conceived the term agile transformation in the same way ('Extensive (covering the entire software development) change to adopt agile methods, practices and ways of working'). However, also Rodríguez et al. did not limit the usage of agile with specific definitions [8].

A general limitation due to our survey design is that we did not ask the respondents to identify their organization. Consequently, we cannot tell the number of different responding companies. Rodríguez et al. acknowledged the same in this kind of survey research [8]. Due to the confidentiality reasons we refrain from evaluating how 
representative our respondent sample is with respect to all Finnish industries. However, the respondents represented several different business domains (see Table 2).

\section{Conclusions}

Based on a recent survey conducted in Finland in 2018, in this paper we have explored the current state of Agile with respect to how extensively organizations are actually transforming themselves and in what ways in practice. Most of the surveyed respondents perceived to be in organizations which have already conducted agile transformations or are currently doing so. Different organizations have used different strategies and tactics but external consultant support is often utilized.

Further work will be done to analyze the survey results more broadly and deeply with cross-tabulations covering more questions than was possible in here. Digitalization may affect companies in different business domains and industries differently.

Our future research plans include repeating the survey study in certain other countries and also annually in Finland. That would make it possible to do more extensive comparative and longitudinal analysis.

Furthermore, our questionnaire can be refined and improved based on the experiences of this first survey round. Considering large agile transformations, a refinement could be to enquire whether the transformation covers the company fully (enterprise agility) or partially - and how exactly (only software development/IT or certain functions/levels) [10, 11]. Additional context factors to support the results analysis could be what particular business environment variables, regulations, certifications or other such requirements and constraints influence the software development of the company. Naturally, already the business domains (Table 2) inform such factors in general.

\section{References}

1. Kettunen, P., Laanti, M.: Future software organizations - agile goals and roles. Eur. J. Futures Res. 5, 16 (2017)

2. Kettunen, P., Laanti, M.: Combining agile software projects and large-scale organizational agility. Softw. Process: Improv. Pract. 13(2), 183-193 (2008)

3. Kettunen, P.: Systematizing software-development agility: toward an enterprise capability improvement framework. J. Enterp. Transform. 2(2), 81-104 (2012)

4. Laanti, M.: Agile transformation model for large software development organizations. In: Proceedings of the XP2017 Scientific Workshops, Article No. 19. ACM, New York (2017)

5. Moe, N.B., Dingsøyr, T.: Emerging research themes and updated research agenda for largescale agile development: a summary of the 5th international workshop at XP2017. In: Proceedings of the XP2017 Scientific Workshops, Article No. 14. ACM, New York, (2017)

6. Laanti, M., Kettunen, P.: SAFe adoptions in Finland: a survey research. In: XP 2019 7th International Workshop on Large-Scale Agile Development (LargeScaleAgile) (in press)

7. Version One 12th Annual State of Agile Report. https://stateofagile.versionone.com. (conducted between August and December 2017). Accessed 10 Mar 2019 
8. Rodríguez, P., Markkula, J., Oivo, M., Turula, K.: Survey on agile and lean usage in finnish software industry. In: ESEM 2012 Proceedings of the ACM-IEEE International Symposium on Empirical Software Engineering and Measurement, pp. 139-148. ACM, New York (2012)

9. Finnish Software Industry Survey. http://www.softwareindustrysurvey.fi/focus-on-flexibili ty-agility-in-software-development/. Accessed 10 Mar 2019

10. Goldman, S.L., Nagel, R.N., Preiss, K.: Agile Competitors and Virtual Organizations: Strategies for Enriching the Customer. Van Nostrand Reinhold, New York (1995)

11. Ronzon, T., Buck, J., Eckstein, J.: Making companies nimble - from software agility to business agility. IEEE Softw. 36(1), 79-85 (2019)

Open Access This chapter is licensed under the terms of the Creative Commons Attribution 4.0 International License (http://creativecommons.org/licenses/by/4.0/), which permits use, sharing, adaptation, distribution and reproduction in any medium or format, as long as you give appropriate credit to the original author(s) and the source, provide a link to the Creative Commons license and indicate if changes were made.

The images or other third party material in this chapter are included in the chapter's Creative Commons license, unless indicated otherwise in a credit line to the material. If material is not included in the chapter's Creative Commons license and your intended use is not permitted by statutory regulation or exceeds the permitted use, you will need to obtain permission directly from the copyright holder. 